\title{
Predictors of Osteoporosis in Patients with Moderate Chronic Obstructive Pulmonary Disease on Inhaled Corticosteroid
}

\author{
Fatemah A. El-Shabacy ${ }^{1}$, Sherry K. Abd El-Rahman ${ }^{1}$, \\ Amal El-Maghraby ${ }^{2}$, Eman R. Amer ${ }^{3}$ \\ Departments of Rheumatology and Rehabilitation ${ }^{1}$, Internal Medicine ${ }^{2}$, \\ Clinical Pathology ${ }^{3}$, Benha Teaching Hospital; Egypt
}

\begin{abstract}
Background: Patients with chronic obstructive pulmonary disease (COPD) are at increased risk of osteoporosis because of their age, limited physical activity, smoking, malnutrition and use of corticosteroid. Inhaled corticosteroid (IC) is used in COPD as these agents decrease the frequency of exacerbations. Objectives: To assess bone mineral density (BMD), serum osteocalcin and marker of bone turnover in patients with COPD treated with IC (Beclomethasone). Subjects \& Methods: Sixty Patients with moderately severe COPD, according to the criteria of GOLD committee, under IC therapy for at least one year, were assessed clinically and by evaluation of BMD. In addition, biomarkers of bone turn over, urinary hydroxyproline, total pyridinoline, and biomarker of bone formation, serum osteocalcin, were assessed. The results were compared to 20 age and sex matched healthy individuals serving as a control group. Results: There were $28(46.7 \%)$ male and $32(53.3 \%)$ female patients. T-score was highly significantly lower in COPD patients in comparison to control. Osteocalcin level was significantly lower in patients than in control group $(\mathrm{P}<0.05)$. Urinary pyridinoline level was highly significant higher in COPD group compared with control $(\mathrm{P} \leq 0.001)$. Urinary hydroxyproline level was non significantly lower in patients than control $(\mathrm{P}=0.06)$. $\mathrm{T}$-score was significantly inversely correlated with serum osteocalcin, and urine pyridinoline levels, while it was not significantly correlated with neither patient's age nor hydroxypyroline level. Conclusion: Regular evaluation of osteocalcin and BMD would be helpful for detecting any detrimental changes of bone in COPD patients under long term IC therapy. [Egypt J Rheumatology \& Clinical Immunology, 2015; 3(1): 47-53]
\end{abstract}

Key Words: COPD, BMD, osteocalcine, pyridinoline.

\section{INTRODUCTION}

Chronic obstructive pulmonary disease (COPD) is characterized by a progressive airflow limitation that is not fully reversible and is associated with an abnormal inflammatory response of the lung to noxious particles and gases ${ }^{1}$. COPD comprises a major health burden with an estimated global prevalence of $9-10 \%$ in adults of 40 years and older ${ }^{2,3}$. The GOLD guidelines include "significant extra pulmonary effects" in the definition of COPD, indicating that COPD can be considered a multicomponent disease with marked extra-pulmonary effects. ${ }^{4-7}$ These extra pulmonary effects may contribute to the morbidity and mortality in COPD patients. Examples of these effects are loss of muscle mass (with and without abnormal loss of body weight ${ }^{8}$, increased fat mass ${ }^{9}$ and arterial stiffness. ${ }^{10}$ Moreover, COPD patients have a higher risk of osteoporosis as compared to healthy subjects. ${ }^{11}$ Indeed, COPD has been included in male osteoporosis For Correspondence: farah_ali926@yahoo.com risk estimation score. ${ }^{12}$ Osteoporosis is a systemic skeletal disease characterized by a low bone mass and/or micro architectural deterioration of bone tissue leading to increased bone fragility and increased fracture risk. In COPD, the prevalence of osteoporosis is assumed to be two to five folds higher than in age-matched subjects without airflow obstruction. The burden of osteoporosis varies with the incidence of fractures risk. ${ }^{13}$ Fractures of the hip, vertebrae and forearm are the most common fractures in patients with osteoporosis, although fractures of other body parts can also be the result of osteoporosis. Especially in COPD patients it is important to prevent vertebral fractures since they might result in a decreased forced vital capacity. ${ }^{14}$ Identified correlates of osteoporosis or a low BMD in COPD patients are body composition measures, disease severity and treatment with corticosteroids. ${ }^{15}$ Osteoporosis is under diagnosed and under treated in COPD patients and the underlying mechanisms remain unclear. To date, screening recommendations for osteoporosis in COPD patients are not available. ${ }^{16}$ 
The gold standard for the diagnosis of osteoporosis is dual energy absorptiometry (DXA). Multiple sites can be used to measure BMD by DXA. The sites most frequently used are the hip, the lumbar spine, forearm and/or whole-body. ${ }^{17}$ Most studies in COPD patients use DXA scan only to determine osteoporosis, therefore micro architectural changes without a low BMD are missed. When osteoporosis is based on DXA-scan only age is usually not an independent predictor of osteoporosis. ${ }^{18}$

This study was performed to assess bone mineral density (BMD), serum osteocalcin and marker of bone turnover in patients with COPD treated with IC.

\section{SUBJECTS AND METHODS}

Sixty patients with a known diagnosis of COPD were considered eligible for the study if they met the following inclusion criteria: age between 20 and 50 years; with moderate severity COPD according to the criteria of GOLD committee $^{1}$ and under IC "Beclomethasone" therapy for at least one year. Patients were excluded on the basis of one or more of the following criteria: Rheumatic diseases or other diseases affecting bone or calcium homeostasis, including secondary hyperparathyroidism and endocrinopathy. In addition to 20 age and sex matched healthy individuals serving as a control group. All patients and control group were assessed clinically and were evaluated by bone mineral density (BMD) measure. Biomarkers of bone turn over; urinary hydroxyproline and total pyridinoline, biomarker of bone formation; serum osteocalcin were assessed also. All patients had signed written consent before the start of procedure.

\section{Measurement of osteocalcin:}

Osteocalcin was measured by ELISA method with commercially available kits from bioscience, Rffymetrix Company. Principle of the assay; an anti human osteocalcin monoclonal coating antibody was adsorbed on to micro wells. Human osteocalcin present in the sample or stand and bound to antibodies absorbed to the micro wells, an HRP conjugated monoclonal anti-human osteocalcin antibody binds to human osteocalcin captured by the first antibody following incubation unbound enzyme conjugated anti-human osteocalcin was removed during awash step and substrate solution reactive with HRP was added to the wells. A colored product is formed in proportion to the amount of soluble human osteocalcin present in the sample. The reaction was terminated by addition of acid. Human osteocalcin concentration was determined from standard curve. ${ }^{19}$
Measurement of urinary hdroxyproline (HYP) and pyridinoline (PYD):

HYP and PYD were measured by ELISA method with commercially available kits from WKEA, USA. Principle of the assay: Purified human HYD or PYD antibody coated micro titer plate wells to make solid-phase antibody, then PYD antigen in the sample was added to wells. Combined HYD or PYD antibody with enzyme labeled was added to form antibody-antigen-enzyme antibody complex. After washing completely, substrate was added which becomes blue color. HRP enzyme- catalyzed reaction is terminated by the addition of sulphyric acid solution and the color change was measured. pectrophotometrically at wave length of $1.50 \mathrm{nv}$. The concentrate of HYP or PYD in the samples was then determined from standard curve. ${ }^{20}$

Local dual energy absorptiometry (DXA) scan of hip and lumbar spine was made in both control and COPD patients. With DXA technique the amount of mineral in the scanned area of bone is measured in grams and divided by the measured bone surface in square centimeter to acquire a definite bone mineral density (BMD). The BMD score of patients is expressed as $\mathrm{T}$ score. This $\mathrm{T}$ score is calculated by measuring how many standard deviations the patient's BMD differs from the mean BMD of a young control population. DXA osteoporosis was defined by a Tscore of $\leq-2.5$, osteopenia as T-score between -1 and 2.5 and normal BMD: T-score $>-1 .^{10}$

\section{Statistical Analysis}

The collected data were tabulated and analyzed using SPSS version 16 soft ware (SPSS) Inc, Chicago, ILL Company). Categorical data were presented as number and percentages while continuous data were expressed as mean \pm standard deviation (SD). Student " $t$ " test, Pearson's correlation coefficient (r) were used as tests of significance. Multiple logistic linear regression analysis for predicting $\mathrm{T}$-score value from other variables was done. The accepted level of significance in this work was stated at $0.05(\mathrm{P} \leq 0.05)$ was considered significant, $\mathrm{P} \leq 0.001$ was considered highly significant.

\section{RESULTS}

The study included 60 COPD patients with moderate severity; $28(46.7 \%)$ male and $32(53.3 \%)$ female patients. Their age ranged from 20-50 years in males, and 20-45 years in females with mean of $(44.4 \pm 2.4)$ years. The control group included 20 subjects, 8 males $(40 \%)$ and 12 females $(60 \%)$ with mean age $(39.1 \pm 5.6)$ years. 
T-score was highly significantly lower in COPD patients than control. Regarding bone markers and $\mathrm{T}$ scores; serum osteocalcin level was significantly lower in patients than in control group $(\mathrm{P}<0.05)$, urinary pyridinoline level was highly significant higher in COPD group compared with control $(\mathrm{P} \leq 0.001)$ and urinary hydroxyproline level was non significantly lower in patients than control $(\mathrm{P}=0.06)$ (Table 1).

There was significant difference of $\mathrm{T}$-score between male and female in control group $(\mathrm{P}<0.05)$, while this difference was not statistically significant among patients $(\mathrm{P}>0.05)$ (Table 2$)$.
T-score was significantly inversely correlated with serum osteocalcin, and urine pyridinoline level ( $\mathrm{P}=0.01$ and 0.001 , respectively), while it was not significantly correlated with neither patients age nor hydroxypyroline level (Table 3, Figures 1 and 2). There was no significant correlation between different parameters of bone turn over in COPD patients (Table 4).

Logistic regression model was done to find equation to predict $\mathrm{T}$ - score from other significant values, which equation is : $(\mathrm{T}$-score $=-2.22+(.82 \mathrm{x}$ osteo $)+(.01 \mathrm{x}$ pyrido $)$ (Table 5$)$.

Table 1. Comparison of T-score, Osteocalcin, hydroxyproline and pyridinoline among patients and control group.

\begin{tabular}{|c|c|c|c|c|}
\hline & Patients $(n=60)$ & Control $(n=20)$ & $\mathbf{T}$ & $\mathbf{P}$ \\
\hline $\begin{array}{c}\text { T-score, mean } \pm \text { SD } \\
(\text { Range })\end{array}$ & $\begin{array}{c}-1.3 \pm 2.6 \\
-(2.6-3.5) \\
\end{array}$ & $\begin{array}{l}-1.47 \pm 0.22 \\
-(1.2-1.9) \\
\end{array}$ & 8.02 & $0.001 * *$ \\
\hline $\begin{array}{c}\text { Osteocalcin }(\mathrm{ng} / \mathrm{ml}) \text { mean } \pm \mathrm{SD} \\
\text { (Range) }\end{array}$ & $\begin{array}{l}1.8 \pm .4 \\
1.5-2.5\end{array}$ & $\begin{array}{l}2.8 \pm 0.37 \\
2.4-3.5\end{array}$ & 10.3 & $0.01 *$ \\
\hline $\begin{array}{r}\text { Hydroxyproline (ug/24h urine } / \mathrm{m}^{2} \text { ), mean } \pm \text { SD } \\
\text { (Range) }\end{array}$ & $\begin{array}{l}13.2 \pm 2.9 \\
8.3-22.5 \\
\end{array}$ & $\begin{array}{l}16.2 \pm 6.5 \\
2.5-23.2\end{array}$ & 2.00 & 0.06 \\
\hline $\begin{array}{c}\left.\text { Pyridinoline (ug } / 24 \mathrm{~h} \text { urine } / \mathrm{m}^{2}\right), \text { mean } \pm \text { SD } \\
\text { (Range) }\end{array}$ & $\begin{array}{c}51.1 \pm 4.4 \\
45-58\end{array}$ & $\begin{array}{c}32.7 \pm 8.5 \\
22-53\end{array}$ & 12.5 & $0.001 * *$ \\
\hline
\end{tabular}

*significant, **highly significant

Table 2. Comparison between male and female as regards $\mathrm{T}$ score in patients and control group.

\begin{tabular}{ccccc}
\hline T-score & Male & Female & T & P \\
\hline Patients $(\mathrm{n}=60)$ mean \pm SD & $-1.9 \pm 2.1$ & $-0.7 \pm 2.9$ & 1.88 & 0.07 \\
Range & $-3.4 / 3.5$ & $-3.6 / 2.3$ & & \\
\hline Control $(\mathrm{n}=20)$ mean \pm SD & $-1.6 \pm 0.27$ & $-1.38 \pm 0.13$ & 2.40 & $0.03^{*}$ \\
Range & $4.3 /-1.9-$ & $-1.2 /-1.5$ & & \\
\hline * significant & & &
\end{tabular}

* significant

Table 3. Correlation of T-score with age, serum osteocalcin, urine hydroxypyroline and pyridinoline in COPD patients.

\begin{tabular}{lcc}
\hline & $\mathbf{R}$ & $\mathbf{P}$ \\
\hline T-score / Age & -0.09 & 0.39 \\
T-score / osteocalcin & -0.47 & $0.01^{*}$ \\
T-score / HYD & -0.09 & 0.39 \\
T-score / PYD & -0.47 & $0.00^{* *}$ \\
\hline
\end{tabular}

HYD; hydroxypyroline, PYD; pyridinoline *significant, **highly significant

Table 4. Correlation between markers of bone turnover and bone formation.

\begin{tabular}{lcc}
\hline & $\mathbf{R}$ & $\mathbf{P}$ \\
\hline HYD/PYD & -.04 & 0.83 \\
HYD./osteocalcin & -.27 & 0.23 \\
PYD/ ostecalcin. & -.01 & 0.95 \\
\hline
\end{tabular}

HYD; hydroxypyroline, PYD; pyridinoline 
Table 5. Multiple logistic linear regression for predicting T-score value from other variables.

\begin{tabular}{lcccc}
\hline & B & SE & T & P \\
\hline Constant & -2.22 & 1.72 & -1.29 & 0.19 \\
Osteocalcin & -0.82 & 0.59 & -1.39 & 0.169 \\
PYD & 0.10 & 0.02 & 4.32 & 0.00 \\
\hline
\end{tabular}

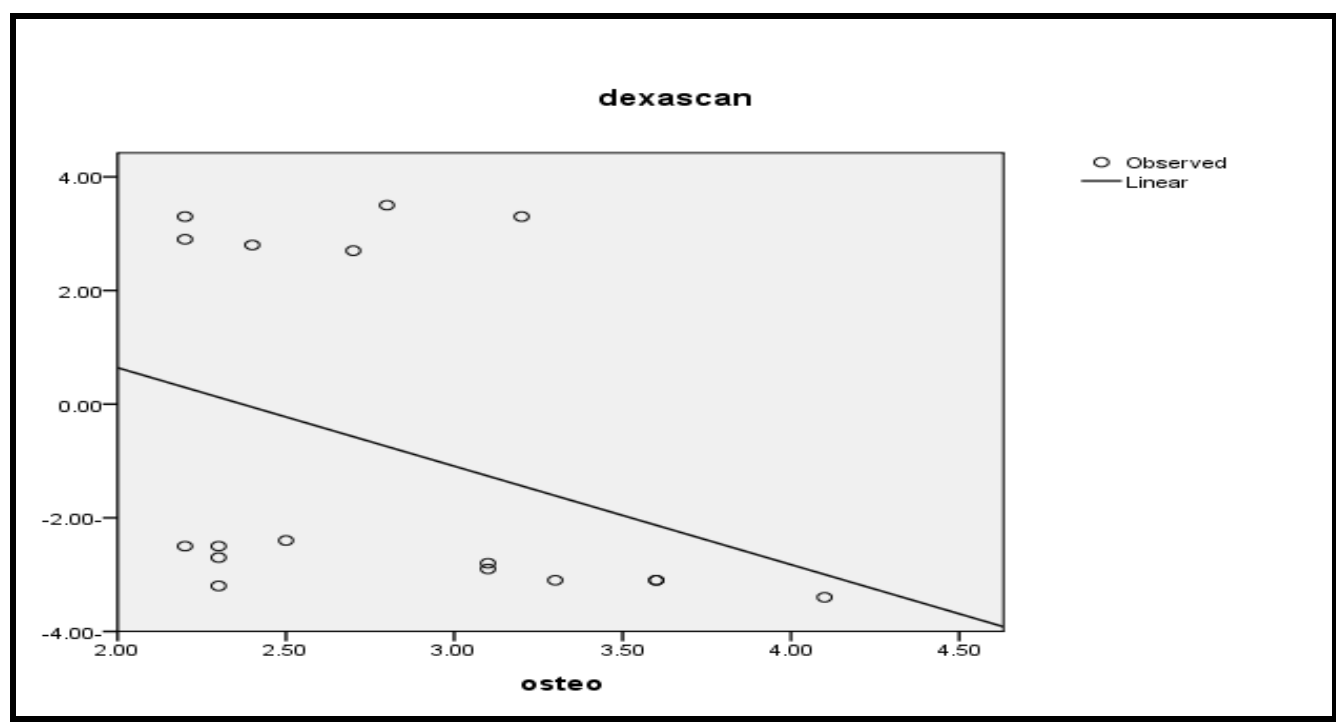

Figure 1. Correlation between patients T-score and osteocalcin.

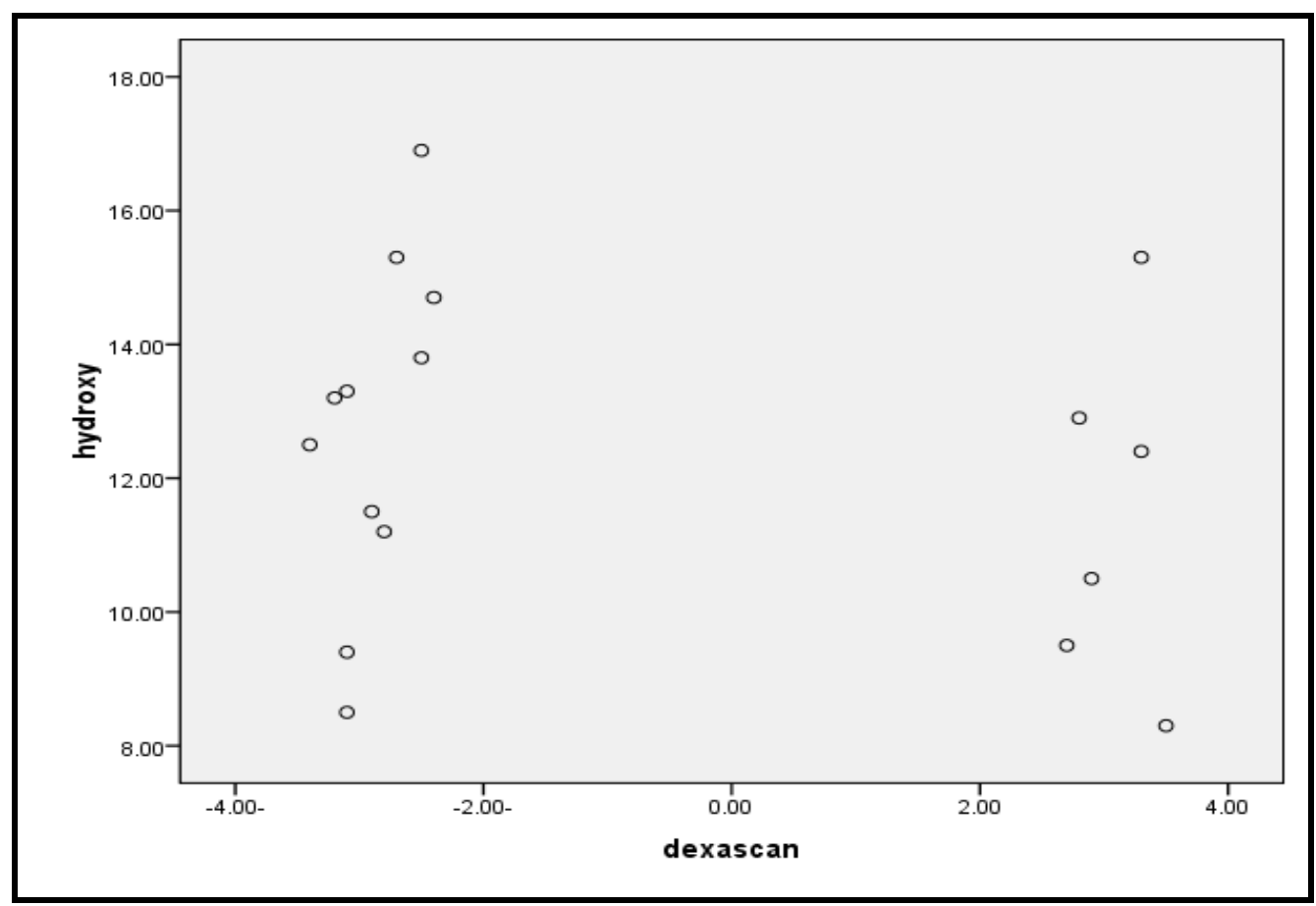

Figure 2. Correlation between patients T-score and hydroxyproline. 


\section{DIsCussION}

Patients with COPD are at increased risk of osteoporosis because of their limited physical activity, smoking, malnutrition and use of corticosteroids. Systemic inflammation represents an additional pathomechanism contributing development of osteoporosis in COPD. ${ }^{21}$ Corticosteroids have direct and indirect effects on bone turnover. Bone formation is inhibited during the use of steroids, while bone resorption is elevated or unchanged. ${ }^{22}$ Recent studies haves shown that long term use of inhaled corticosteroid at a moderate or high doses is also associated with increased risk for osteoporosis. In COPD the prevalence of osteoporosis is assumed to be two to five folds higher than in age-matched subjects without air flow obstruction. ${ }^{23}$

BMD can be expressed in standard deviation of means and the $\mathrm{T}$ score. $\mathrm{T}$ score is a standard deviation compared to age and sex matched control population. One standard deviation reduction in the BMD increases the fracture risk by 1.3-3 folds. ${ }^{24}$ In a cross sectional study there was relationship between use of steroid and vertebral fractures in men especially over 50 year of age or older and incidence was increased in inhaler steroid users than non steroid group using only bronchodilators and less than men using continuous systemic steroids. ${ }^{25}$ A comparative study between male patients suffering from COPD over 50 years on beclomethasone inhaler at dose higher than $1500 \mathrm{mcg}$ showed higher risk of vertebral fracture in comparison with patients on inhaled 32 agonist only. ${ }^{26,27}$ These results were matched with the current study which showed highly significant difference between patients and control group as regards $\mathrm{T}$ score $(\mathrm{P}<0.001)$, low BMD was more common in COPD patients on inhaled corticosteroids (IC).

This study showed that there was significant correlation between $\mathrm{T}$ score and the age of control group $(\mathrm{P}<0.01)$, while it was not significantly correlated with age of COPD patients. This means that IC could play a role in osteoporosis development irrespective to the age of the patients. Serum osteocalcin is considered a specific marker of osteoblast function, as its levels correlate with the bone formation rate. In a study of 31 patients with moderate to severe asthma who had been receiving more than 1000 microgram beclomethasone per day for more than two years, low level of osteocalcin was observed. ${ }^{28}$ These results came in agreement with the results of this study which showed significantly lower level of osteocalcin in COPD patients than in control group $(\mathrm{P}<0.05)$.

In concordance with these results Dinc and his colleagues, reported that serum osteocalcin was significantly lower in COPD patients on beclomethasone inhaler for one year, than in the control group. ${ }^{29}$ Although osteoporosis is based on BMD assessment, bone markers (urinary hydroxproline, urinary pyridinoline) can be useful in selected cases to improve the assessment of fracture risk when BMD measurement by itself does not provide clear answer. In some studies the mean values for markers of bone turn over are higher in osteoporosis patients than in the matched controls. ${ }^{30} \mathrm{In}$ our study there was no significant difference between patients and controls as regards urinary hydroxyproline $(\mathrm{P}=0.06)$. Moreover, there was no significant correlation between $\mathrm{T}$-score and urinary hydroxyproline in patients group $(\mathrm{P}=0.03)$, while urinary pyridinoline in patients group was significantly correlated with their $\mathrm{T}$-score $(\mathrm{P}=0.01)$. The research reviewed by expert group showed that inhaled corticosteroids has deleterious effect on bone mineral density and associated with low level of osteocalcin and non significant affection of pyridinoline level $^{31}$, disagreed in part with this work which showed highly significant difference of urinary pyridinoline in patients in comparison to control group $(\mathrm{P}<0.001)$. Contrary to the findings of Doull et al. ${ }^{32}$ and Sorva et al. ${ }^{33}$, who reported no significant change in osteocalcin in asthmatic children treated with ICS, we found a significant decrease in serum osteocalcin levels. Our study came in agreement with the study conducted on 70 patients with COPD received 800 microgram beclomethasone/Day to evaluate markers of bone turn over, osteocalcin was decreased but there was no changes in hydroxyproline level among these patients. ${ }^{34}$ A study conducted on young healthy male volunteers, received low dose of prednisone, showed decreased serum osteocalcin level in $22 \%$, while no changes were found in urinary pyridinoline and hydroxyproline levels ${ }^{35}$ which came in concordance with the results of the current study. Unfortunately, the usefulness of biochemical markers of bone turnover is limited, because none can reliably predict those who will lose bone mass and the degree to which it might be lost as a result of corticosteroid treatment. The serum and urine levels of the bone turnover markers show a remarkable variability, which may be as high as $40-50 \%$. $^{36}$

The variability in the levels of bone turnover markers is explained by biological factors such as: growth, age, gender and body weight, ethnicity and geography, pregnancy and lactation, diet, food intake, exercise and mobility, menstrual and seasonal cycles, circadian variation, previous fracture, the metabolic bone disease, hepatic and/or renal insufficiency. ${ }^{37}$ From all these studies, which came in agreement with our results we concluded that the main marker affected by long-term use of IC corticosteroids in COPD was osteocalcin. Statistically designed Logistic regression 
model done to find equation to predict T-score from another significant values found that osteocalcin was the best marker of bone turn over that can predict value of T-score. Osteocalcin, a non collagenous matrix protein in bone, is produced exclusively by osteoblasts. In most conditions, bone resorption and formation are tightly coupled, and osteocalcin level reflects bone turn over. ${ }^{36}$

In Conclusion, prolonged use of Inhaled corticosteroid by COPD patients especially in higher doses has deleterious effect on BMD. This effect appears as reduction of patients T-score correlated with alteration in biochemical markers of bone turn over mainly reduction of osteocalcin and elevation of urinary pyridinoline level. So, Regular evaluation of BMD using DEXA scan would be helpful for detecting any detrimental changes in COPD patients under long term IC therapy and serum osteocalcin should be estimated regularly as it is the main marker of bone turn over affected in COPD patients treated with IC.

[Disclosure: Authors report no conflict of interest]

\section{REFERENCES}

1. Rabe KF, Hurd S, Anzueto A, et al. Global strategy for the diagnosis, management, and prevention of chronic obstructive pulmonary disease: GOLD executive summary. Am J Respir Crit Care Med 2007; 176(6):532-555.

2. Agusti AG. Systemic effects of chronic obstructive pulmonary disease. Proc Am Thorac Soc 2005; 2(4):367-370.

3. Lopez AD, Mathers CD, Ezzati M, et al. Global and regional burden of disease and risk factors, 2001: systematic analysisof population health data. Lancet 2006; 367(9524):1747-1757.

4. Andreassen H, Vestbo J. Chronic obstructive pulmonary disease as a systemic disease: an epidemiological perspective. Eur Respir J Suppl 2003; 46:2-4.

5. Wouters EF. Introduction. Systemic effects in chronic obstructive pulmonary disease. Eur Respir J Suppl 2003; 46:1s.

6. Schols AM, Broekhuizen R, Weling-Scheepers CA. Body composition and mortality in chronic obstructive pulmonary disease. Am J Clin Nutr 2005; 82(1):53-59.

7. Sabit R, Bolton CE, Edwards $\mathrm{PH}$, et al. Arterial stiffness and osteoporosis in chronic obstructive pulmonary disease. Am J Respir Crit Care Med 2007; 175(12):1259-1265.

8. Holguin F, Folch E, Redd SC, et al. Co morbidity and mortality in COPD-related hospitalizations in the United States, 1979 to 2001. Chest 2005; 128(4):2005-2011.
9. Biskobing DM. COPD and osteoporosis. Chest 2002; 121(2):609-620.

10. WHO Scientific Group on the Prevention and Management of Osteoporosis. Prevention and Management of Osteoporosis: report of a WHO scientific group. Http; //whqli bdoc who int/trs/WHO_TRS_921 pdf (2007).

11. Abe E, Sun L, Mechanick J, et al. Bone loss in thyroid disease: role of low TSH and high thyroid hormone. Ann N Y Acad Sci 2007; 1116:383-391.

12. Compston JE. Risk factors for osteoporosis. Clin Endocrinol (Oxf) 1992; 36(3):223-224.

13. Lumachi F, Camozzi V, Ermani $\mathrm{M}$, et al. Bone mineral density improvement after successful parathyroidectomy in pre- and postmenopausal women with primary hyperparathyroidism: a prospective study. Ann N Y Acad Sci 2007; 1117:357-361.

14. Bolton CE, Ionescu AA, Shiels $\mathrm{KM}$, et al. Associated loss of fat-free mass and bone mineral density in chronic obstructive pulmonary disease. Am J Respir Crit Care Med 2004; 170(12):12861293.

15. Shepherd AJ, Cass AR, Carlson CA, et al. Development and internal validation of the male osteoporosis risk estimation score. Ann Fam Med 2005(6):540-546.

16. Leech JA, Dulberg C, Kellie S, et al. Relationship of lung function to severity of osteoporosis in women. Am Rev Respir Dis 1990; 141(1):68-71.

17. Bapoje SR, Whitaker JF, Schulz T, et al. Preoperative evaluation of the patient with pulmonary disease. Chest 2007; 132(5):1637-1645.

18. Ioda, leday N, Agasaka Y. Secondary osteoporosis. Inhaled corticosteroids induced osteoporosis in respiratory diseases, Clin Calcium, 2007; Jun; 17(6):955-62.

19. M, Hoyle NR, Wieczorek L, eds. Bone Markers: Biochemical and Clinical Perspectives. London: Martin Dunitz Ltd;( 2001).

20. Laitinen O, Nikkila EA, Kivirikko KI. Hydroxyproline in the serum and urine. Normal values and clinical significance. Acta medica Scandinavica. Mar 1966; 179(3):275-28.

21. Grove A, McFarlane LC, Jackson CM, et al.; Effects of short term exposures to inhaled corticosteroids on novel biochemical Markers of bone metabolism. Eur J Clin Pharmacol.1996; 50: 275-277.

22. Staa, T van. The pathogenesis, epidemiology and management of glucocorticoid-induced osteoporosis. Calcif Tissue Int 2006; 79: 129-137.

23. BuyukkaplanUS, Akkaya A, Yildiz M, Brican et al. Mineral status of COPD patients under long-term inhaled Corticosteroid therapy, J Prosthodont. 2008Aug; 17(6): 462-7.

24. Marshall D, Johnell O, Wedel H. Meta-analysis of how well measures of bone- mineral density predict occurrence osteoporotic fractures. BMJ 1996; 312:1254-1259. 
25. Mc Evory CE, Ensrud KE, Bender E, et al. Association between corticosteroid use and vertebral fractures in older men with obstructive pulmonary disease.Am J Rrespir Crit Care Med. Ma 1998; 157 (3pt4): 704-9.

26. Wheelock C, Gloss J, St Anna L. clinical inquiry. Do inhaled steroids reduce bone mineral density and increase fracture risk; J Fam Pract, 2012; Aug, 61(8): 493-508.

27. Gonneli S, Caffarelli C, Maggi S, Guglielmi G, Siviero P, Rossi S, Crepaldi G, et al.; Effect of inhaled glucocorticoids and 32 agonists on vertebral fracture risk in COPD patients: The Edo study. Neur Cir 2010; Aug, 87(2):137-43.

28. Gagnon L, Boulet LP, Brown Y, et al. Influence of inhaled corticosteroids and dietary intake on bone density and metabolism in patients with moderate to severe athma. J Am Diet Assoc.1997; (12):140-6.

29. Dinc M, Tchugunova y, Dinc S, et al. Decreased osteocalcin levels in patients with chronic obstruction

pulmonary disease using long term inhaled beclomethasone dipropionate. Metabolism 2001; 50 (11):1336-9.

30. Younes M, Hachfi H, Ouertani D, et al. Utility of biochemical Markers of bone turnover in diagnosis of osteoporosis and fracture risk prediction. Tunis Med.2014; 92(5):304-10.
31. Seibel, M.J., R. Eastell, C.M. Grundberg, et al. Biochemical markers of bone metabolism. In pages 1543-1572 of principle of bone biology 2002. 2nd ed. J.P. Bilezikian, L.G. Raisz \& G.A. Rodan, Eds. Academic Press. San Diego.

32. Doull I, Freezer N, Holgate S; Osteocalcin, growth and inhaled corticosteroids: a prospective study. Arch. Dis.Child. 1996; 74: 497-501.

33. Sorva R, Turpeinea M, Junturen-Backman K, et al. Effects of inhaled budesonide on serum markers of bone metabolism in children with asthma.J. Allergy. Clin. Immunol. 1992; 90: 808-15.

34. Kerstjens AK, Brand PL, Dekhuijzen PN, et al. Effects of short-term and long-term treatment with inhaled corticosteroids on bone metabolism in patients with airways obstruction. Dutch CNSLDstudy group. Thorax.1994; 49(7):652-6.

35. Lems WF, Van Veen GJ, Gerrits MI, et al. Effect of low-dose prednisone (with calcium and calcitriol supplementation) on calcium and bone metabolism in healthy volunteers. Br J Rheumatol.1998:37(1):27339 .

36. Hannon RA, Eastell R: Bone markers and current laboratory assays. Cancer Treat Rev 2004. 32(suppl1):7.

37. Hannon, R. \& R Eastell. Preanalyical variability of biochemical markers of bone turnover. Osteoporosis. Int. 112000 (Suppl. 6): S30-S44. 